\title{
PHYSICAL ACTIVITY LEVELS DURING A 6-WEEK, SCHOOL-BASED, ACTIVE VIDEOGAMING INTERVENTION USING THE GAMERCIZE POWER STEPPER IN BRITISH CHILDREN
}

\author{
Michael J. Duncan ${ }^{1(\mathrm{~A}, \mathrm{~B}, \mathrm{C}, \mathrm{D}, \mathrm{E}, \mathrm{F})}$, Samantha Birch $^{1(\mathrm{~A}, \mathrm{~B}, \mathrm{D}, \mathrm{E})}$, Lorayne Woodfield $^{2(\mathrm{~B}, \mathrm{D}, \mathrm{E},)}$, Joanne Hankey $^{1(\mathrm{~B}, \mathrm{D}, \mathrm{E})}$ \\ ${ }^{1}$ Department of Biomolecular and Sports Science, Coventry University, UK \\ ${ }^{2}$ Department of Physical Education and Sports Studies, Newman University College UK
}

\begin{abstract}
Introduction: Active video games have been purported to offer an alternative means by which children can be physically active but few data have examined this issue in ecologically valid settings. This study sought to assess physical activity levels during active videogame play and compare this to 'free play' associated with recess activity in a sample of British primary school children.

Methods: Forty children (ages 10-11, 20 boys, 20 girls) from central England were randomly selected to participate in a 6 week, lunchbreak based, active video gaming intervention $(n=20)$ or act as controls $(n=20)$. Repeated measures analysis of covariance (controlling for body mass index) was used to examine any differences in physical activity, determined by pedometry and heart rate monitoring.

Results: Children in the intervention accumulated significantly greater steps/min than controls during the first week of the intervention. The steps/min values were not significantly different at the mid point or during the last week of the assessment period. Irrespective of time point, children engaging in active video game play spent a lesser percentage of time engaged in MVPA than controls undertaking 'traditional' recess activity.

Conclusion: Active video game physical activity using the Gamercize power stepper appears to be similar to physical activity levels during traditional school lunchbreak over a 6 week period. Active videogaming may therefore provide an alternative means to engage children in physical activity in the school setting.
\end{abstract}

Key words: pedometer, heart rate monitoring, recess, steps, exergaming

\section{Introduction}

It has been accepted by scientists and health practitioners alike that media-based sedentary behaviours such as TV viewing and leisure time computer use compete for time that might otherwise be spent in physical activity, which might lead to obesity $[1,2]$. One particular influence on children's health related behaviour that has received substantial media attention is computer and video game play. Moreover, children today have not only been described as fatter than previous generations, but also less active, less athletically skilled, less interested in physical activity, less self-disciplined (and therefore more likely to choose the 'easy' or 'soft' option, be it with respect to physical activity or food) and more addicted to technology [3]. This has subsequently led researchers to suggest that children's computer/video game behaviour should be the subject of further scrutiny when examining health behaviours $[2,4]$.

Recently, technological advances have led to the development of active video gaming such as the Nintendo Wii, Microsoft Kinect and Sony Playstation
Move, partly in an attempt to convert sedentary screen time to active screen time and to promote children's physical activity. However, evidence supporting this idea is scant and that which is available has tended to be laboratory based. Lannigham-Foster et al. (5) reported that active video game play was associated with increased energy expenditure (EE) compared to resting energy expenditure (REE) and EE during seated gaming. Active gaming, using the Sony Eye Toy $^{\oplus}$, increased EE by $273 \mathrm{kj} / \mathrm{h}$ above REE whereas active gaming using a dance mat game increased $\mathrm{EE}$ $382 \mathrm{kj} / \mathrm{h}$ above REE in 25, 9 year old children. They concluded that activity promoting video games more than doubled the energy expenditure compared with chair-based equivalents and offer a potential approach for reversing sedintariness and reducing pediatric obesity. A further laboratory study by Graves et al. [6] examined energy expenditure during active and sedentary game play in 11, 13-15 year old adolescents. They concluded, similar to Lannigham-Foster et al. [5], that, active video games use significantly greater energy than sedentary game play but are not of suffi- 
cient intensity to contribute towards the recommended daily amount of exercise in children as defined by Trost [7]. However, both these studies were laboratory based, examined the acute impact of active video game play on physical activity and further research examining this issue in other settings and with varied age ranges is needed to more fully understand the physical activity responses to active videogaming $[5,6]$.

Intervention studies have likewise highlighted the potential of active videogames to contribute to children's physical activity. McDougall and Duncan [8] reported that, in a sample of $12,8-11$ year old children who engaged in active videogaming during school recess over one week, children accumulated approximately $10 \%$ of the recommended number of steps/day for health. They however, highlighted the short duration of their study as a limitation and suggested that future research examine the potential of active video game play as a means to enhance children's physical activity at recess over a longer period. Results from a 6-week active videogaming intervention compared Nintendo Wii activity with physical activity accrued during 'normal' lunchbreaks in school children [9] and reported that physical activity (steps/min) during active videogaming was greater than 'normal' lunchbreak on the first week of their intervention but lower thereafter. They suggested that further research examining whether active videogaming might be used to enhance physical activity in the school setting. Similarly, research by Sit et al [10] used direct observation to record physical activity levels and game choice (interactive vs. online games) in 70 Children from Hong Kong during 2,60 minute recreational sessions. They reported that children accrued significantly greater MVPA during interactive video gaming ( $70 \%$ vs $2 \%$ ) compared to online sedentary equivalents and suggested that interactive games can facilitate physical activity in children. Sit et al [10] also reported that given the opportunity children are more likely to suggest active vide games over sedentary versions. Another study [11] examined the feasibility of using a dance video game (Dance Dance Revolution) as a means to increase physical activity and decrease sedentary screen time in a group of 60,7 to 8 year old children by using video games in the home environment for a 28 week period. Using accelerometry to assess physical activity, Maloney et al [11] reported increased vigorous and reduced light physical activity compare to their control group. The Dance video game group also reported a significant decrease in sedentary screen time compared to the control group. The researchers concluded that Dance Dance Revolution reduces sedentary screen time and facilitates slight increases in vigorous physical activity but that further research was needed to better characterise the contexts in which children may use active video games to promote healthier lifestyles.
More recently, Foley and Maddison [4] reviewed studies employing active video games as a means of increasing physical activity in children. They reported that 11 studies focused on quantification of energy costs of active videogames compared to traditional non-active videogames and 8 studies focused on the utility of active video games as an intervention to increase physical activity in children. They concluded that, compared to traditional, non-active videogames, active videogames elicit greater energy expenditure, which was similar in intensity to mild to moderate intensity physical activity. The intervention studies that have been conducted also indicate that active video games may have the potential to increase free-living physical activity and improve body composition in children. However, methodological limitations of these interventions, including not using a control group and failure to randomise conditions $[8,12]$, have prevented definitive conclusions as to the efficacy of active videogaming as a means to augment children's physical activity. Furthermore, the majority of studies have been laboratory based, examining an acute bout of videogame play. As such the real world applicability of these technologies in enhancing physical activity has yet to be determined with subsequent call for researchers to examine this technology in settings that are ecoologically valid (i.e., settings that mirror how this technology might be used outside the laboratory). There has also been inconsistency in the measurement of physical activity with studies using questionnaires, pedometers and accelerometers. This is an important consideration as the type of movement generated during active gaming needs to be carefully considered when selecting a means to objectively quantify physical activity [4]. Consequently, there is a need to examine the effect of active videogame interventions on children's physical activity to determine whether this technology is effective in promoting physical activity in children. The purpose of this study was exploratory and to assess physical activity levels during active video game play and compare this to 'free play' associated with recess activity in a sample of British primary school children over a 6 -week period.

\section{Material and Methods Study Design}

The study used a quasi-experimental intervention design whereby children from two primary schools in England were randomly allocated to intervention or control groups. The two schools were drawn from electoral wards that were similar in terms of ethnic and socioeconomic status. They were both based in an urban city environment within the West Midlands of the United Kingdom. The intervention group undertook twice weekly active video gaming sessions 
during school lunch breaks for 6 weeks with another group acting as controls.

\section{Participants}

Following ethics approval and parental informed consent, 40 children ( 20 boys, 20 girls) from 2 primary schools in central England were randomly selected to participate. Children were from school year 6 (ages 10-11) and the mean age (SD) of the children was $10.8(0.4)$ years. Twenty children (10 boys and 10 girls) undertook twice weekly sessions of active video gaming during school lunch breaks with 20 children ( 10 boys and 10 girls) acting as controls. There was an equal gender split in both the intervention and control groups and there was no difference in habitual physical activity levels of intervention and control groups determined via 4 days of pedometer monitoring prior to the intervention period.

\section{Procedure}

The intervention group undertook twice weekly active video game play sessions instead of their regular recess activity for 6 weeks. A 6-week intervention period was chosen as it fitted within a standard school-term and was thus pragmatic in terms of the intervention being run within the school environment. The control group took part in their normal recess activity only. Active video game play sessions used the XBOX 360 games console and the Gamercize power stepper. The Gamercize Power Stepper system consists of an exercise stepping machine which interfaces with commonly available video game systems and their controllers. Participants must step on the Gamercize power stepper at a minimum cadence of 30 steps/ min in order for the videogames controller to remain active and thus enable the children to play the videogame system. Game titles were rotated during the intervention period and consisted of Sega Superstars Tennis, Fifa 09, Proevolution Soccer, Sega Rally, Lego Batman. Prior studies have suggested that game titles may not be sufficiently attractive enough to children for consistent play to occur and have thus, resulted in reductions in physical activity on a week by week basis. The use of multiple game titles in the current study was employed to ensure the active game play sessions remained attractive to the children concerned. The use of different game titles also had no impact on the physical activity accrued during the intervention period due to the way in which the Gamercize power stepper works (i.e., a set cadence to ensure the games controller remains active for play.

Provision of playground space (in terms of area) and equipment in terms of quantity of fixed items (e.g., monkey bars, climbing frames) and portable items (balls, cones, hoops, etc) across both schools that participated in the study was similar in terms of area and equipment provided during recess $(P>.05)$. In addition, the duration of school recess periods was identical across schools.

Physical activity was assessed at recess during the first, third and sixth weeks of the 6-week period for both groups using pedometry and heart rate monitoring. Pedometer determined physical activity was assessed using a sealed, piezo-electric pedometer (New Lifestyles, NL2000, Montana, USA) which was worn throughout the gameplay and recess periods on the front of the iliac crest, in accordance with the manufacturers guidelines. As both modes of activity (recess and stepping on the videogames console) required ambulatory activity as their major means of activity, pedometry was well suited to capture the physical activity undertaken during both the recess and active videogame play periods. The pedometer used has been shown to be valid and highly reliable [13]. Furthermore, given that no studies have been undertaken which have validated the use of pedometers on portable steppers in children, pilot work was undertaken with a group of 10-11 year old children $(n=5)$ comparing step counts determined via the NL2000 pedometer with actual steps completed assessed via hand tally counter whilst stepping on the Gamercize Power Stepper for a 5 min period. This indicated a highly significant relationship $(r=.98)$ and no significant difference $(P=.05)$ between actual steps taken and those counted by the pedometer. The physical activity monitoring/game play periods were set at 30 minutes across schools and across intervention and control groups. However, step counts were converted to steps/min in order to account for minor variations in the time engaged in recess activity between groups across the monitoring period and in accordance with recommended guidelines [14]. In addition, heart rate data was collected using Polar RS400 heart rate monitors (Polar Electro, OY, Finland), covered with a purpose built shield to prevent children gaining feedback during recess periods. Heart rate was recorded every $5 \mathrm{~s}$. The Heart rate monitor and methods of assessing heart rate employed in the study have been shown to be reliable and valid as a means to assess physical activity in young people [15]. Resting heart rate was determined a priori by averaging the 5 lowest recorded heart rate values recorded for each child [16] lying supine for a 10 minute period in a darkened room. These were determined 24 hours prior to the intervention beginning but following familiarisation sessions described below. Heart rate reserve (HRR) values of $50\left(\mathrm{HRR}_{50}\right)$ and $75\left(\mathrm{HRR}_{75}\right)$ percent were used as threshold values to represent moderate-to-vigorous physical activity (MVPA) and in agreement with prior studies of children's recess based activity [17]. In all cases monitors/pedometers were placed on the children prior to the start of their lunch recess period 
and the children consumed their lunches at the end of the recess period in order to ensure that heart rate measurements were not affected by dietary induced thermogenesis following lunch.

Prior to allocation to groups, measurement of stature (to the nearest $0.1 \mathrm{~cm}$ ) was recorded using a Leicester Height Measure (Seca Ltd., Birmingham, UK). Body mass was assessed using calibrated scales (Seca Ltd., Birmingham, UK) from which body mass index $\left(\mathrm{BMI} \mathrm{kg} / \mathrm{m}^{2}\right)$ was determined. In addition, children were familiarised with the physical activity monitoring equipment to be used in the study and habitual physical activity was assessed using a pedometer worn over 4 days ( $2 \mathrm{X}$ weekday, $2 \mathrm{X}$ weekend) in accordance with recommended guidelines for determining habitual activity [18]. There were no significant differences in BMI or average steps/day between control and intervention groups $(P>0.05)$.

The children undertaking the active video game play sessions were also familiarised with the Xbox and Gamercize Power Stepper system to be used as part of the study. Brief focus group interviews ( $\mathrm{n}=6$ approx per group) were also employed prior to any physical activity assessment/video game sessions in order to ascertain children's prior experience with video games in general and the Xbox specifically. These indicated that all the children possessed at least 1 video game console, $40 \%$ owned the same console that was used in the current study and $100 \%$ had experience of using/playing the same console that was used in the current study.

\section{Statistical Analysis}

Any differences in physical activity across the 6-week period and between intervention and control groups were examined using 3 (Measurement period) by 2 (group) repeated measures Analysis of Covariance (ANCOVA) controlling for body mass index. The dependant variables were the percentage of time spent in MVPA, average heart rate and the steps/min taken at each measurement point. Independent t-tests were also used to examine any differences in the dependant variables between active video gaming and control groups on weeks 1, 3 and 6 of the measurement period. In this instance, t-tests were employed as pairwise comparisons commonly employed when significant differences are found within ANCOVA cannot be used where there is an interaction between a within-subjects variable (e.g., Steps/min) and between a betweengroups variable (e.g., intervention vs. control group). The statistical package for social sciences (Version 16) was used for all analysis and the alpha level was set at $P<.05$. In addition, the contribution of active video game and traditional lunchbreak in meeting the recommended steps/day for healthy weight [19] was also determined.

\section{Results}

In regard to pedometer data, repeated measures ANCOVA indicated a significant measurement period by group interaction $\left(\mathrm{F}_{2,70}=2.966, P=.05\right)$ with number of steps/min being greater for the intervention group on the first week of the intervention period but lower than the control group at the mid and end points of the 6-week period (See Figure 1). Bonferroni post hoc pairwise comparisons indicated no significant differences between steps/min across time periods for the active videogame group (all $P>$ .05) but significantly lower steps/min taken on the first week of the intervention compared to the mid point of the intervention (Mean Diff $=-14.02, P=.05$ ) and between the first week of the intervention and the last week of the intervention (Mean Diff $=-18.98, P=.003$ ) for the control group. Independent t-tests examining any differences in steps/min between the active video gaming and control groups on weeks, 1, 3 and 6 indicated that that steps/min was significantly higher for the intervention group compared to the control group in week 1 (t $36=3.177, P=.003)$ but that the steps/ min values were not significantly different at the mid point $(P=.988)$ or during the last week of the assess-

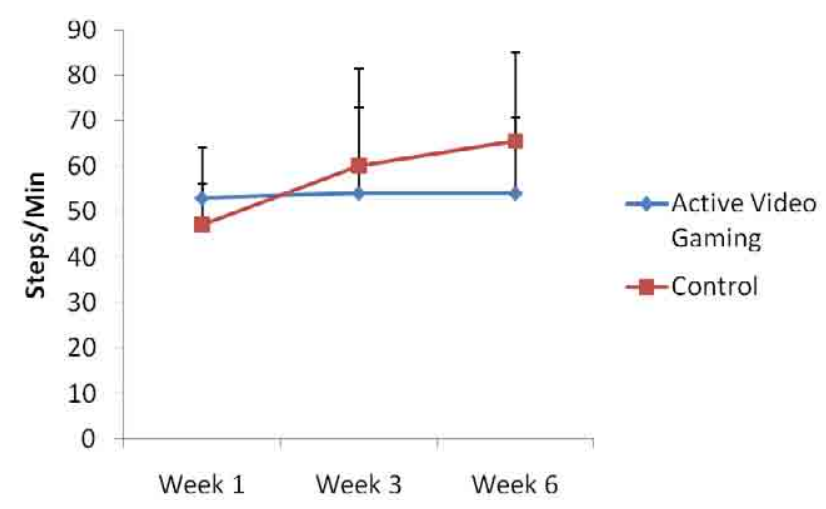

Fig. 1. Mean (SD) of Steps/Min between intervention and control group during the first, third and final week of the intervention period

Table 1. Mean (SD) of steps/min and percentage of time spent in MVPA across the monitoring period

\begin{tabular}{cccccc}
\hline & $\begin{array}{c}\text { Steps/Min } \\
\text { Week1 }\end{array}$ & $\begin{array}{c}\text { Steps/Min } \\
\text { Week3 }\end{array}$ & $\begin{array}{c}\text { Steps/Min } \\
\text { Week6 }\end{array}$ & $\begin{array}{c}\text { MVPA Week 1 } \\
\text { (\%time) }\end{array}$ & $\begin{array}{c}\text { MVPA Week 6 } \\
\text { (\%time) }\end{array}$ \\
\hline Active Gaming $(\mathrm{n}=20)$ & $52.9(11.1)$ & $54(16.8)$ & $53.9(16.7)$ & $14.3(8.3)$ & $18.4(6.0)$ \\
Control $(\mathrm{n}=20)$ & $46.5(9.1)$ & $60.6(21.5)$ & $65.5(19.4)$ & $18.0(7.0)$ & $23.4(12.1)$ \\
\hline
\end{tabular}


ment period $(P=.628)$. In terms of heart rate, there were no significant differences in average heart rate or percentage of time spent in MVPA $(P<0.05)$ across time or between groups. Mean (SD) of steps/day and percentage of recess time spent in MVPA and average heart rate for both groups and across the intervention period are presented in Table 1.

\section{Discussion}

The purpose of this study was to assess physical activity levels during active video game play using a novel videogame technology over a 6 -week period and to compare this to 'free play' associated with recess activity in a sample of British primary school children. The results from this exploratory study broadly suggest that active videogame play sessions using the Gamercize power stepper are similar to the levels of physical activity that children engage in during traditional lunchbreak/recess activity. In the present study active video game sessions contributed between 11 to $16 \%$ of the recommended daily step/counts for healthy weight whereas traditional lunch break activity accounted for 9-19\% of this recommended cut-point [19].

Prior laboratory research has concluded that active video games may have potential to positively influence children's physical activity but that energy expenditure during active game play is not comparable to acute bouts of physical activity such as treadmill walking $[5,6]$. Similarly, a recent school based study by Duncan and Staples [9] examined twice weekly lunchtime sessions with the Nintendo Wii as compared to physical activity engaged in during 'traditional' lunchbreak. In their study, there was an acute effect of active video game play whereby physical activity (Steps/Min and percentage of time spend in MVPA) during recess was greater for those children engaging in active video game play compared to those engaging in regular recess during the first week of their intervention. However, this was not sustained for the remainder of their intervention. They concluded that active videogaming may not be sufficient to contribute meaningfully to children's energy expenditure in comparison to other forms of physical activity [8,9]. This is in contrast to recent work by Maloney et al [11] which reported longer term (28 weeks) increases in vigorous physical activity and reductions in sedentary screen time when a dance based active video game was employed in the home setting. However, In the case of their study, although vigorous activity increased over the time period where their active video game was employed, Maloney et al [11] reported that robust changes in MVPA were not found as it is relatively difficult to increase MVPA in youth and easier to reduce sedentary screen time. They also concluded that such active video games might be better used in school settings outside of statutory physical education.
Thus, the results of the present study offer promise as physical activity accrued when using the Gamercize power stepper was not significantly different to that engaged in during school lunch break. It is however unclear why the control group's physical activity level was lower than that of the intervention group in week 1. The weather did not restrict free play and there appeared to be no other factor that would have restricted the children's physical activity during this period. Nevertheless, the level of physical activity was also sustained over a 6 -week period. These findings may predominantly be due to the way in which the Gamercize Power stepper interfaces with the video game console. As this form of active videogaming necessitates a minimum cadence of stepping in order for the videogame controller to work, and thus to enable the child to play the videogame, a consistent level of physical activity has to be maintained in order for participants to play the game. Thus, the motivational basis for children to use the Gamercize power stepper is different to that employed by other active video gaming options such as the Nintendo Wii, Dance mat systems such as those operated by Zig Zag or Dance Dance Revolution. In all these cases, energy expenditure is predicated on interaction within the games. As such the motivation to engage in activity comes from a desire to interact within the gaming experience with physical activity being integral to immersion in the narrative of the game play [8]. Conversely, the mechanism by which physical activity may be maintained when using the Gamercize power stepper appears to be more through the reinforcement of playing the game when exercise is maintained and the withdrawal of game play when exercise ceases and so is explicitly linked with behaviourism.

Some caution is needed when making these conclusions. The results of statistical analysis indicated that ambulatory physical activity accrued during active video game play was higher during the first week and not significantly different during the third and final week of the intervention period compared to the steps/ minute values attained during traditional lunch break. This is despite mean values for the control group being greater than mean scores for the active video gaming group in both weeks 3 and 6 of the intervention. Indeed, mean data for the control group indicates that they reached the threshold for MVPA based on steps min (60-63 steps/min) as identified by Scruggs et al (20) in weeks 3 and 6 . This would in some way appear paradoxical. However, there was greater variability in steps/min scores for physical activity accrued during traditional lunch break for the control group. This anomaly may perhaps be due to greater restriction of the range of physical activity that can be engaged in during active video games using the power stepper whereas the free play associated with traditional lunch 
break activity would lead to greater inter-individual variation in physical activity levels with resultant higher standard deviations for a given mean value. In the Gamercize Power Stepper condition, the children may have learnt to control the stepping rate to enable the video game controller to work and not step at a greater rate than this required resulting in a lower mean value with a corresponding smaller spread of values around the mean.

This is in contrast to prior studies [9,21]. In their study Duncan and Staples [9] noted that practice using the Nintendo Wii games and controllers may change the level of energy expenditure required to be successful within these games. It is possible that the reductions in physical activity seen in the study by Duncan and Staples, as the children progressed through the 6-week intervention, may have arisen because they actually become more successful at the games they were playing. Prior authors have also suggested that active video game play might provide a stimulus for obesity treatment and prevention due to increases in energy expenditure measured in comparison to sedentary game play [5]. In the context of this study and school recess, perhaps use of active videogame technology, such as that employed in the current study, could offer an alternative opportunity for children to engage in physical activity, particularly for children who are not attracted to other more traditional modes of physical activity. However, the results of the current study are not sufficient to answer this question.

As this study was school-based, lunch time physical activity was employed in order to provide a comparison for the physical activity undertaken during active video game play sessions as well as providing a means to compare results to the only other published studies of school-based active videogaming $[8,9]$. Prior research has reported that children can accumulate substantial portions of their daily-recommended physical activity levels during the free-play associated with recess periods [22] and clearly, the benefit of traditional recess free play in terms of encouraging physical activity make this a period where children can be physically active.

The current study is not without its limitations. Active video game play was engaged in twice weekly as this was considered to be a realistic frequency for this form of activity in schools. It is possible that different weekly frequencies of game play may have provided different results. Furthermore, this study did not track physical activity after completion of the intervention period so no conclusion can be made as to the effect of active videogaming interventions on long term physical activity behaviour. This may be a beneficial future research focus. Sample size is also an issue, these results are based on a relatively small sample of participants and further large scale studies are needed to verify these findings. Additionally, one other concern, is that despite providing a novel way to play video games, if children do not want to play them or enjoy playing video games, this mode of activity intervention may actually be counter productive and may explain the weak effects reported in this study. This latter point is important as enjoyment of a physical activity is a key determinant influencing the allocation of time to that pursuit $[23,24]$. Specifically, if children enjoy exergaming, participation in this behaviour over a prolonged period may ultimately benefit PA engagement and accrual [25]. However, to date, only one study [25] has examined enjoyment of exergaming and in this study only Nintendo Wii Fit was examined. With the increasing advances of exergaming technology it is important for researchers to not only assess energy costs of the range of exergaming modalities but also children's enjoyment of these to understand whether exergaming may have a place in physical activity promotion. Enjoyment was not assessed in the present study but researchers should look to incorporate this variable into future studies examining the efficacy of exergames. More specifically, using a counter-balanced design that accounted for preference of play might give a fuller insight into Gamercize's true impact on physical activity levels. Given the research by Sit et al [10] which showed that children are more likely to choose an active video game compared to a sedentary alternative, understanding the role that enjoyment and other psychological process may play in choice of leisure time activity may be useful in promoting healthy lifestyles in children.

The current study employed pedometry and heart rate monitoring as a means to assess the physical activity accrued during both active videogaming and traditional lunchbreak sessions. These were chosen as both modes of exercise under scrutiny employed ambulatory physical activity for the most part and these means of activity assessment have been used to examine physical activity levels during active videogaming [9] and school lunchbreaks $[17,26]$ respectively. Pilot data also indicated that the pedometers in the present study were able to accurately capture the steps accrued during Gamercize Power Stepping. However, alternative modes of activity assessment such as accelerometry may be more sensitive in assessing children's physical activity.

This appears to be the first scientific study of physical activity using the Gamercize power stepper and as yet, no authors have assessed the energy cost of this form of activity. Future laboratory based studies would be ideally placed to examine this. Furthermore, a thorough evaluation is needed to establish if and how active videogaming is a viable means to promote physical activity behaviour change in pediatric populations. 


\section{Conclusion}

This study has added further data on children's physical activity responses to novel active videogame technology and by comparing a sustained period of active video game play to traditional lunchbreak physical activity in an ecologically valid setting (i.e., the school). In this case, physical activity during active game play was similar to the physical activity engaged in traditional lunchbreak during a 6-week intervention period. This suggests that school health practitioners such as the school nurse, teacher of lunchtime supervisors could employ active video gaming, using the Gamercize power stepper, as one potential, alternative, way to contribute to children's physical activity at school.

\section{Acknowledgements}

This research was supported by a research grant from the Economic Challenge Investment Fund.

\section{References}

1. Andersen RE, Crespo CJ, Bartlett SJ, at al. Relationship of physical activity and television watching with body weight and level of fatness among children. JAMA 1998; 279: 938-42.

2. Mota J, Ribeiro JC, Santos PM. Obesity, physical activity, computer use and TV viewing in Portuguese adolescents. Ped Exer Sci 2006; 18:113-21.

3. Gard M, Wright J. The Obesity Epidemic, Science, Morality and Ideology. London, Routledge; 2005.

4. Foley L, Maddison R. use of active video games to increase physical activity in children: A (virtual) reality? Ped Exer Sci 2010; 22:7-20.

5. Lanningham-Foster L, Jensen TB, Foster RC, et al. Energy Expenditure of sedentary screen time compared with active screen time for children. Pediatrics 2006; 118: 1831-5.

6. Graves L, Stratton G, Ridgers ND. Comparison of energy expenditure in adolescents when playing new generation and sedentary computer games: Cross sectional study. BMJ 2007; 335: 1282-4.

7. Trost SG, Pate RR, Sallis JF, et al. Age and gender differences in objectively measured physical activity in youth. Med Sci Sports Exerc 2002; 34: 350-5.

8. McDougall J, Duncan MJ. Children, Videogames and Physical Activity: An exploratory Study. Int J Disability Hum Dev 2008; 7: 89-94.

9. Duncan MJ, Stapes V. The impact of a school-based active video game play intervention on children's physical activity during recess. Human Movement 2010; 11: 95-9.

10. Sit CH, Lam JW, McKenzie TL. Direct observation of children's preferences and activity levels during interactive and online electronic games. J Phys Act Health 2010: 7; 484-9.

11. Maloney AE, Betea C, Kelsey KS, et al. A pilot of a video game (DDR) to promote physical activity and decrease sedentary screen time. Obesity 2008: 16; 2074-80.

12. Madsen KA, Yen S, Wlasinuk L, et al. Feasibility of a dance videogame to promote weight loss among overweight children and adolescents. Arch Pediatr Adolesc Med 2007; 161: 105-7.
13. Crouter SE, Schneider P, Bassett DR. Spring-levered versus piezoelectro-pedometer accuracy in overweight and obese adults. Med Sci Sports Exerc 2005; 37: 1673-9.

14. Jago R, Watson K, Baranowski T, et al. Pedometer reliability, validity and daily activity targets among 10 -to- 15 year-old boys. J Sports Sci 2006; 24: 241-51.

15. Ekelund U, Poortvliet E, Yngve A, et al. Heart rate as an indicator of the intensity of physical activity in human adolescents. Eur J App Physiol 2001; 85: 244-9.

16. Janz KF. Use of heart rate monitors to assess physical activity. In: Welk GJ. (Ed.), Physical Activity Assessments for Health-Related Research. Human Kinetics, Champaign, IL; 2002;143161.

17. Ridgers ND, Stratton G, Clark E, et al. Day-today and seasonal variability of physical activity during school recess. Prev Med 2006; 42: 372-4.

18. Trost SG, Pate RR, Freedson PS, et al. Using objective physical activity measures with youth: how many days of monitoring are needed. Med Sci Sports Exerc 2000; 32: 426-31.

19. Tudor-Locke C, Pangrazi RP, Corbin CB, et al. BMI-referenced standards for recommended pedometer determined steps/day in children. Prev Med 2004; 38: 857-64.

20. Scruggs PW, Beveridge SK, Eisenman PA, et al. Quantifying physical activity via pedometry in elementary physical education. Med Sci Sports Exerc 2003; 35: 1065-71.

21. Sell K, Lillie T, Taylor J. Energy expenditure during physically interactive video game playing in male college students with different playing experience. J Am Coll Health 2008; 56: 50511.

22. Verstraete S, Cardon G, DeClercq D. Increasing children's physical activity levels during recess periods in elementary schools: The effects of providing game equipment. Eur J Pub Health 2006; 16: 415-9.

23. Dishman RK, Motl RW, Saunders R, et al. Enjoyment mediates effects of school-based physical-activity intervention. Med Sci Sports Exerc 2005; 37: 478-48.

24. Kolt GS, Driver RP, Gils LC. Why older Australians participate in exercise and sport. J Aging Phys Act 2004; 12: 185-98.

25. Graves LEF, Ridgers ND, Williams K, et al. The physiological cost and enjoyment of Wii Fit in adolescents, young adults and older adults. J Phys Act Health 2010; 7: 393-403.

26. Beiglhe A, Morgan C, Le Masurier G, et al. Children's physical activity during recess and outside school. J Sch Health 2006; 76: 516-20.

Received: January 04, 2011

Accepted: June 01, 2011

Published: June 06, 2011

Address for correspondence:

Dr Michael J. Duncan

Department of Biomolecular and Sports Sciences

Coventry University, Priory Street, Coventry, CV1 5HB

E-mail: michael.duncan@coventry.ac.uk

Samantha Birch: aa0052@coventry.ac.uk

Lorayne Woodfield: 1.a.woofield@newman.ac.uk

Joanne Hankey: ab0397@coventry.ac.uk

\begin{tabular}{llll}
\hline Authors' contribution & B - Data Collection & D - Data Interpretation & F - Literature Search \\
A - Study Design & C - Statistical Analysis & E - Manuscript Preparation & G - Funds Collection
\end{tabular}

